\title{
The effects of AIDS prevention programs by lay health advisors for migrants in The Netherlands
}

Citation for published version (APA):

Martijn, C., de Vries, N. K., Voorham, T., Brandsma, J., Meis, M., \& Hospers, H. J. (2004). The effects of AIDS prevention programs by lay health advisors for migrants in The Netherlands. Patient Education and Counseling, 53, 157-165. https://doi.org/10.1016/S0738-3991(03)00125-3

Document status and date:

Published: 01/01/2004

DOI:

10.1016/S0738-3991(03)00125-3

Document Version:

Publisher's PDF, also known as Version of record

Document license:

Taverne

Please check the document version of this publication:

- A submitted manuscript is the version of the article upon submission and before peer-review. There can be important differences between the submitted version and the official published version of record.

People interested in the research are advised to contact the author for the final version of the publication, or visit the DOI to the publisher's website.

- The final author version and the galley proof are versions of the publication after peer review.

- The final published version features the final layout of the paper including the volume, issue and page numbers.

Link to publication

\footnotetext{
General rights rights.

- You may freely distribute the URL identifying the publication in the public portal. please follow below link for the End User Agreement:

www.umlib.nl/taverne-license

Take down policy

If you believe that this document breaches copyright please contact us at:

repository@maastrichtuniversity.nl

providing details and we will investigate your claim.
}

Copyright and moral rights for the publications made accessible in the public portal are retained by the authors and/or other copyright owners and it is a condition of accessing publications that users recognise and abide by the legal requirements associated with these

- Users may download and print one copy of any publication from the public portal for the purpose of private study or research.

- You may not further distribute the material or use it for any profit-making activity or commercial gain

If the publication is distributed under the terms of Article $25 \mathrm{fa}$ of the Dutch Copyright Act, indicated by the "Taverne" license above, 


\title{
The effects of AIDS prevention programs by lay health advisors for migrants in The Netherlands
}

\author{
Carolien Martijn ${ }^{\mathrm{a}, *}$, Nanne K. de Vries ${ }^{\mathrm{b}}$, Toon Voorham ${ }^{\mathrm{c}}$, Jeanine Brandsma ${ }^{\mathrm{c}}$, \\ Max Meis ${ }^{\mathrm{d}}$, Harm J. Hospers ${ }^{\mathrm{a}}$ \\ a Department of Experimental Psychology, Faculty of Psychology, University of Maastricht, \\ P.O. Box 616, 6200 MD Maastricht, The Netherlands \\ ${ }^{\mathrm{b}}$ Department of Health Education and Health Promotion, University of Maastricht, The Netherlands \\ ${ }^{c}$ Municipal Health Service, Rotterdam, The Netherlands \\ ${ }^{\mathrm{d}}$ Department of Public Health, Municipality of Groningen, The Netherlands
}

Received 10 June 2002; received in revised form 28 February 2003; accepted 23 March 2003

\begin{abstract}
Two studies describe the effectiveness of acquired immunodeficiency syndrome (AIDS) prevention programs by lay health advisors (LHAs) for migrants in The Netherlands. The effects of such AIDS programs were evaluated (Study 1) and compared with the effects of professional health advisors (PHAs, i.e. medical doctors or nurses) (Study 2). The first study concerned Turkish and Moroccan migrants and showed positive effects on knowledge, behavioral control, and social norm towards condom use. Iraqi refugees participated in the second study that concerned a direct comparison of LHA- and PHA-based programs. Both programs result in positive effects in terms of attitude change and knowledge, but the LHA program resulted in a stronger intention to discuss AIDS with children. Analyses predicting intention to use condoms provide evidence that LHA programs lead to a stronger relation between attitudes and intention. This suggests that LHA-based AIDS programs are more successful in inducing internally motivated intentions to safe sex practices, such as condom use. (C) 2003 Elsevier Ireland Ltd. All rights reserved.
\end{abstract}

Keywords: AIDS prevention; Migrants; Lay health professionals; Peer education; Effect evaluation

\section{Introduction}

Education is an important strategy to prevent infection with the human immunodeficiency virus (HIV) that causes the acquired immunodeficiency syndrome (AIDS). Therefore, effective communication strategies are needed to inform people, and to convince them to engage in safe sex practices. In The Netherlands, efforts have been made to reach the general public by using a mass media approach. Also, numerous AIDS prevention activities on a smaller scale have been tailored to the needs of specific target groups. For instance, health services become increasingly aware of the fact that a tailored approach is needed to effectively reach migrants in The Netherlands. Officially, there are about 2 million members of ethnic minorities living in The Netherlands in 2000, making up about $13 \%$ of the total Dutch population. The largest ethnic minorities are Surinamese, Turkish and Moroccan (267,000, 297,000

\footnotetext{
* Corresponding author. Tel.: +31-43-388-4067; fax: +31-43-388-4196. E-mail address: c.martijn@psychology.unimaas.nl (C. Martijn).
}

and 253,000 inhabitants, respectively [1]). It is estimated that there are also about 50,000-200,000 asylum seekers and refugees who are not registered (yet). The majority of the asylum seekers originate from Iraq, Afghanistan, Yugoslavia, Bosnie-Hercegovina and Somalia (8300, 7118, 4289, 3769, 2775 asylum requests in 1998, respectively [2]).

In 1989, the National Committee on AIDS Control set up a specific Migrant AIDS Prevention Project in order to ensure that migrants, like the Dutch, receive adequate information on how to protect themselves against HIV. Such information should be culturally relevant and sensitive to cultural differences $[3,4]$. It is realized that merely translating an information brochure, putting ethnic names into it and replacing photographs with pictures of people with different hair and skin color is not sufficient. The most important groups of migrants in The Netherlands, the Turkish and Moroccan communities, will not, or only partly, be reached by such information, because they less often use written information materials but use other media [5]. Furthermore, the need for culturally appropriate education strategies seems especially relevant in the case of AIDS 
prevention. Because of its relation to sexual behavior, AIDS can be considered as a delicate and not easily debatable issue in several ethno-cultural minority communities [6].

In this article, we will discuss the effects of an AIDS education strategy that was specifically designed to reach different ethno-cultural groups that are not easily reached by regular activities. In this education strategy, members of an ethno-cultural group were trained to give AIDS education, in their own language, to other people of their ethno-cultural group. These members are called paraprofessionals or lay health advisors (LHAs). A LHA is an individual who is indigenous to his/her community and consents to be a link between community members and a health service system [7]. In The Netherlands, training in AIDS education for LHAs is coordinated on a national level by the National Institute for Health Promotion and Disease Prevention (NIGZ). Twelve regional support centers offer part-time AIDS education-training programs (total of 12 meetings in 2 months followed by three refresher courses a year). LHAs are required to master the Dutch language and to have completed intermediate vocational education. Other important selection criteria are affinity with one's one ethnic community and 'life experience' [8]. Apart from providing future LHAs with actual information about HIV-transmission and AIDS, education-training programs focus on enhancing social skills (i.e. speech and listening skills, facilitating group discussions). LHAs who successfully finish their training are likely to work in a variety of settings such as cultural festivals, community centers, coffee houses, and mosques. Characteristic of most of the LHA-based AIDS education programs in The Netherlands is that LHAs often work in small group settings and aim at actively engaging listeners to discuss the supplied information $[9,10]$.

It is assumed that LHAs are more effective than professional advisors who are assisted by an interpreter in several respects and because of several reasons. Obviously, a first advantage is the language similarity. But, the biggest advantage probably is the understanding of a community's cultural context [11]. A member of the same cultural group has a better understanding of norms and values about AIDS and sexuality, and knows how to discuss the issue in an acceptable manner.

Although the advantages of employing LHAs seem self-evident, there is little direct empirical evidence for the greater effectiveness of the use of LHAs for migrants over a professional advisor. Only a few studies provide indirect effect evaluations of LHA-based programs. Janz et al. [12] interviewed the coordinators of 37 AIDS prevention projects and asked them which strategies they judged the most promising. The coordinators reported the use of LHAs as the third most effective strategy, after small group discussions and the use of outreach workers for high risk populations. Watkins et al. [13] evaluated a LHA-based program that aimed at stimulating Latina farmworker women in rural North Carolina to visit childcare centers and prenatal care centers. Latina mothers who had contact with a
LHA made significantly more sick child visits and were more likely to make the recommended number of prenatal visits than mothers who had no contact with a LHA. Also, Latina women who had contact with a LHA were more knowledgeable about health practices than women without contact. A successful breast cancer screening program is reported by Earp et al. [14]. Older, rural African-American female LHAs instigated long-term individual changes in screening behavior. Baker et al. [15] described a health advocacy program for a Latin American community in which LHAs successfully served as intermediaries between their community and health services. Some direct evidence for the effectiveness of LHAs is found in the field of peer education, a method in which adolescents give advice to other adolescents [16]. For example, Rijke and De Vries [17] reviewed 17 evaluation studies on health education programs by peer educators. In more than half of the cases, a program was more effective when an adolescent gave advice rather than a teacher or another adult; no instances of reduced effectiveness were reported.

Also Bernert and Mouzon [18] conclude in their recent literature review on the effectiveness of peer education that empirical evidence for the superiority of peer-led programs is scarce. In this article, we will describe two studies in which we systematically try to analyze the effectiveness of AIDS education by LHAs for migrants in The Netherlands. The first study concerned Turkish and Moroccan participants, and compared pre-intervention data with post-intervention data. The second study concerned AIDS education for Iraqi participants. These participants were randomly assigned to a session facilitated by a LHA or to a Dutch public health nurse (and an interpreter). The design of the second study allowed us to test the hypothesis that LHAs are more effective in bringing about changes in behavioral determinants than health professionals. The aim of interventions in both studies was to enhance knowledge of the transmission of HIV and how transmission can be prevented, to take away misunderstandings and unnecessary fears, and to influence the attitude and efficacy toward condom use in a positive direction. The ultimate goal was to stimulate participants to engage in safe sex practices, such as the use of condoms when having sex with casual partners. As a theoretical framework to analyze the effectiveness of the intervention, we used the theory of planned behavior [19]. The theory of planned behavior states that the intention to adopt a given behavior (i.e. condom use) is the best predictor of behavior. The intention to perform a certain behavior is the result of three determinants. The first determinant comprises an individual's attitude or the perceived costs and benefits. The second determinant refers to the perceived social norms on performance of the behavior. The third determinant is perceived behavioral control, which reflects personal beliefs about the ease or difficulty of adopting the behavior in question. The theory of planned behavior has proven to be an adequate model to predict condom use $[20,21]$ among different ethno-cultural communities [22]. 


\section{Study 1}

\subsection{Methods}

\subsubsection{Research setting}

Participants of Study 1 were new inhabitants of the city of Rotterdam and mainly had the Turkish or Moroccan nationality. They followed an introductory course of the Newcomer Integration Project (a project in which newly arrived immigrants learn the Dutch language and about Dutch society and culture) in which one session was reserved for AIDS education purposes. Separate education meetings were organized for Turkish and Moroccan and other Arabic-speaking participants. Four LHAs agreed to participate in our study: two Turkish male LHAs and two Moroccan male LHAs. The aim of the education meeting was to pass on knowledge about AIDS and HIV and to stimulate AIDS preventive behavior (i.e. condom use in casual sexual relationships). The meeting lasted about $2 \mathrm{~h}$ including a $30 \mathrm{~min}$ discussion. Using slides and posters, the lay health advisor provided information about the incidence of AIDS, spread over the world, viral infection, transmission routes, heterosexual and homosexual contact, pregnancy and misunderstandings concerning transmission. Condom use as a prevention strategy for infection was emphasized. Several types of condoms were shown, the availability of condoms was mentioned and the proper use of condoms was demonstrated on a model. During the talk and at the end, the audience was actively invited to pose questions or to offer discussion themes.

The aim of this study was to assess whether AIDS education by means of LHAs results in an increase in knowledge about AIDS and HIV, and a more favorable attitude and social norm towards the use of condoms as a means to protect oneself against HIV. Furthermore, we assessed whether AIDS education led to higher perceived behavioral control and a more positive intention to use condoms.

\subsubsection{Design and procedures}

We evaluated the effects of a total of eight AIDS education meetings of which five were organized for Turkish participants and three for Moroccan participants. Knowledge about HIV and AIDS, and the attitude, social norm, perceived behavioral control and intention towards condom use were measured using a questionnaire both before and after each education session. The pretest took place 2 weeks before the education session whereas the posttest was administered 2 weeks after the session. The posttest consisted of the same questions as the pretest. The questionnaires were phrased in Turkish or classic Arabic and were filled out by participants individually.

\subsubsection{Measures}

Sociodemographics: Sociodemographic variables included nationality, year and month of residence in The Netherlands, educational level and sex, age, marital status.
Sociodemographic variables were categorized as follows: country of birth (1: Turkish, 2: Moroccan, 3: different nationality such as Tunesian, Sudanese, Iraqi), residence (1: less than a year prior to the meeting, 2: longer than a year prior to the meeting), educational level (1: low education level (primary school), 2: higher education level (secondary school or more)), sex (1: male, 2 : female), age $(1=18-25$ years old, $2=26-35$ years old), marital status ( 1 : married, 2: single).

Knowledge about AIDS: Twenty statements intended to measure the knowledge about AIDS and could be answered with true, false or do not know. The statements all related to the transmission, prevention and characteristics of HIV and AIDS (e.g. "Only homosexual men can get AIDS", "Infection with HIV can be prevented by washing yourself after intercourse"). In order to create a knowledge index, we first recoded the answers. Correct answers were coded as 1, and incorrect or do not know answers as 0 . Then the scores were added which resulted in an AIDS knowledge index with a minimal score of 0 (no correct answers) and a maximum score of 20 (all answers correct). Cronbach's alphas were 0.83 at pretest and 0.86 at posttest.

Attitudes: The attitude towards the use of condoms was measured by nine statements. Participants expressed their (dis)agreement with the statements on a 5-point scale varying from disagree very much to agree very much. An example of a statement is: "Using a condom feels safe". The mean of the nine attitude statements was computed in order to construct one index measuring attitude towards condom use. A low index score indicates a negative attitude towards condom use, a high index score a positive attitude towards condom use. Cronbach's alphas for the attitude index were 0.72 at pretest and 0.68 at posttest.

Social norm towards condom use: The social norm toward condom use was measured with two statements that could be answered on 5-point scales varying from disagree very much to agree very much ("Most people that are important to me think I should use condoms if I have casual partners", "Most Turkish/Moroccan people I know, think I should use condoms if I have casual partners"). A social norm index was computed as the mean score of the two items ( $r$ pretest $0.55, r$ posttest 0.53 ). A low score indicates a negative social norm towards the use of condoms, a high score a positive social norm.

Perceived behavioral control: Participants rated three statements about behavioral control on 5-point scales varying from disagree very much to agree very much (e.g. "I know exactly how to use a condom"). A perceived behavioral control index was constructed by computing the mean of the three statements. A low score indicates low behavioral control, a high score high behavioral control. Cronbach's alphas were 0.63 at pretest and 0.68 at posttest.

Intention to condom use: Three statements measured the intention to use condoms (e.g. "If I have sexual intercourse with a new partner, I will use a condom"). The answers were 
gathered on three 5-point scales varying from I certainly will not to I certainly will. Cronbach's alphas were 0.77 at pretest and 0.63 at posttest.

\subsection{Study 1: Results}

Participants: A total of 75 participants attended to the education meetings and filled out both the pretest and posttest questionnaire. Fifty-one participants received education by a Turkish LHA: all had the Turkish nationality. Twenty-four participants received education in Arabic by a Moroccan health advisor. Of the latter group, 13 persons had the Moroccan nationality and 11 a different nationality (Tunisian, Sudanese and Iraqi). In the discussion of the results, we will distinguish between three nationality groups: Turkish $(n=$ 51), Moroccan $(n=13)$ and other Arabic $(n=11)$. Although the Newcomer Integration Project concentrated on people who migrated to The Netherlands less than a year prior to the meeting, 23 participants lived in The Netherlands longer than 1 year. Another distinction was made between levels of education: 24 participants were relatively low educated (primary school) and 51 received a relatively higher education (secondary or higher education). About two-thirds $(64.9 \%)$ of the participants were between 18 and 25 years old, $35.1 \%$ were between 26 and 35 years old. Three-quarter (75.4\%) was married and $24.6 \%$ was not married and lived alone. Forty-five men and 30 women completed both the pretest and posttest questionnaires. For practical reasons, it was not possible to organize different meetings for men and women separately or to match them to the gender of the LHA.

Analyses: The effects of the education meetings were analyzed for each determinant separately (knowledge about AIDS, attitude, social norm, perceived behavioral control and intention) using ANOVA's with pretest and posttest responses as repeated measurements. For each analysis, we checked whether a possible difference between pre- and posttest responses interacted with demographic variables such as gender, education level, nationality, length of stay, age and marital status.

Knowledge about AIDS: Knowledge about AIDS increased from 12.4 correct answers at pretest, to 16.6 correct answers at posttest $(F(1,73)=162.03 ; P<0.001)$. Knowledge increase interacted significantly with education level $(F(1,73)=27.30 ; P<0.001)$. This interaction was caused by the difference between the lower and higher education groups in the amount of correct answers at pretest (9.1 and 13.9 correct answers, respectively; $F(1,73)=$ $30.03 ; P<0.001)$ which was absent at posttest $(16.2$ and 16.9 , respectively, n.s.). Knowledge increased significantly for both participants with low and high education $(t$ 's 8.10 and 8.36, respectively, $P$ 's $<0.001)$ but the increase was greater in the lower education group, due to lower initial knowledge. Nationality (Turkish, Moroccan or other Arabic), length of stay, sex, age and marital status were not related to knowledge increase.
Attitude towards condom use: The mean attitude score at pretest was 3.42 and the mean posttest attitude score was 3.57 , a marginally significant change in a positive direction $(F(1,71)=3.64 ; P=0.061)$. There is no relation between attitude change and nationality, length of stay, level of education, sex, age or marital status.

Social norm towards condom use: As a result of the intervention, the social norm became more positive, although the difference was marginally significant $(M$ pretest 3.84 , $M$ posttest $4.11 ; F(1,68)=3.25 ; P<0.076)$. Change in social norm interacted significantly with length of stay $(F(1,68)=12.98 ; P<0.01)$. For participants who migrated less than a year ago to The Netherlands, the social norm became more positive ( $M$ pretest $3.57, M$ posttest 4.16 ; $F(1,68)=14.03 ; P<.001)$. The reverse pattern was observed for participants who resided in The Netherlands over a year. In this case, posttest social norm ratings were more negative as compared to pretest ratings ( $M$ pretest $4.43, M$ posttest $3.93 ; F(1,68)=13.05 ; P<0.01)$. Differences in social norm that existed at pretest were no longer observed at posttest. Nationality, level of education, sex, age or marital status were not related to social norm.

Perceived behavioral control: On the posttest participants indicated more behavioral control than on the pretest $(M$ pretest $3.56, M$ posttest $3.80 ; F(1,72)=4.93 ; P<0.05$ ). Increase in perceived behavioral control was not significantly related to nationality, length of stay, level of education, sex, age or marital status.

Intention to use condoms: Posttest scores revealed a higher intention to use condoms as compared to pretest scores $(M$ pretest $3.61, M$ posttest $4.07 ; F(1,70)=21.49 ; P<0.001)$. Increase in intention interacted significantly with length of stay $(F(1,70)=4.95 ; P<0.05)$. The intention to use condoms of participants who migrated less than a year ago increased from 3.37 at pretest to 3.97 at posttest $(F(1,70)=$ 12.54; $P<0.01)$. The score of participants who resided longer than 1 year in The Netherlands was 4.15 at pretest and 4.27 at posttest, a non-significant difference. Change in intention to use a condom was not related to any of the other demographic variables.

Prediction of intention to use condoms: The intention to use condoms was regressed on the predictor variables from Ajzen's theory of planned behavior (see Table 1). Besides attitude, social norm and perceived behavioral control, knowledge about AIDS was included as a predictor variable. At pretest, the multiple correlation was 0.70 . Social norm and perceived behavioral control had significant standardized beta weights ( $\beta$ social norm: $0.46 ; P<0.001 ; \beta$ perceived behavioral control: $0.24 ; P<0.05$ ). At posttest, the multiple correlation was 0.53 . Only attitude had a significant beta weight ( $\beta$ attitude: $0.38 ; P<0.01$ ).

\subsection{Discussion Study 1}

Although the effects of the education program should be interpreted with great care because of the absence of 
Table 1

Summary of regression analysis for variables predicting the intention to use condoms

\begin{tabular}{llllll}
\hline & \multicolumn{2}{l}{ Pretest $(N=70)$} & & \multicolumn{2}{l}{ Posttest $(N=71)$} \\
\cline { 2 - 3 } \cline { 5 - 6 } Variable: & $\beta$ & Multiple $R$ & & \multicolumn{2}{c}{ Multiple $R$} \\
\hline Knowledge & 0.09 & & & -0.03 & \\
Attitude & 0.12 & & & $0.38^{* * *}$ & \\
Social norm & $0.46^{* * *}$ & & & 0.16 & \\
Behavioral control & $0.24^{*}$ & 0.70 & & 0.18 & 0.53
\end{tabular}

Note: Pretest data of five participants, and posttest data of four participants were omitted because of missing data on one of the four variables.

${ }^{*} P<0.05$.

*** $P<0.001$.

a control group, the results seem promising. After the AIDS education session, participants knew more about HIV and AIDS than they did before the session. Especially lower-educated participants seemed to profit; the initially large difference between lower and higher educated participants was disappeared at posttest. This suggests that LHA is especially useful in bridging knowledge gaps. Participants expressed also increased control over condom use and a stronger intention to use condoms with casual partners. The attitude and social norm towards condom use changed in a favorable direction, although these changes were marginally significant.

A surprising finding is that participants who settled themselves in The Netherlands less than a year ago showed an increased positive social norm towards condom use, whereas the social norm of participants who settled themselves longer than a year ago became less favorable. At pretest, the social norm of recent residents was less positive than the social norm of participants who settled themselves longer than a year ago. At posttest, the social norm of both groups was comparable. In other words, the initial difference between both groups seemed to diminish. A possible explanation for this result is that because the education took place in a group setting, participants learned how other participants felt about using condoms with casual partners. This information could have been used as a basis for inferring the social norm. In other words, perhaps the perception whether other important people think that one should use condoms or not, was influenced by the norm within the education group: this led to an increase for participants who initially perceived a relatively negative social norm, but also to a decrease for those who initially perceived a very positive social norm. Length of stay was also related to intentions to use condoms: initial differences between the two groups disappeared resulting in more favorable intentions for participants who settled themselves in The Netherlands less than a year ago.

Interesting results emerged in the regression analyses predicting the intention to use condoms. At pretest, intentions were most strongly related to social norm and perceived behavioral control; at posttest the attitude was the single signif- icant predictor of intention. Thus, stronger intentions were primarily related to stronger attitudes. Although negatively perceived social norms became more positive and control feelings increased, a participant's own, inner convictions seemed to determine whether he or she planned to use condoms. Taken together, Study 1 offered some indication that AIDS education by a LHA may affect the main determinants of condom use in a favorable manner. However, Study 1 was not designed to test whether AIDS education delivered by LHAs is more effective than delivered by a non-similar health professional. Therefore, our second study attempted to provide a more direct test of the effectiveness of LHAs by adding a condition in which participants were educated by a Dutch professional advisor who was assisted by an interpreter. The second study was conducted in a refugee center and carried out with a different population of migrants. All participants were Iraqi refugees who were temporarily accommodated in the center. The refugee center organizes all kinds of courses to prepare refugees for their (often permanent) stay in The Netherlands, including an AIDS education session.

On the whole, the design of Study 2 resembles the design of the first study. About the same questionnaires were used although some questions were rephrased, added or omitted to suit this specific target group. These alterations were made on the basis of interviews with Iraqi men and women, and professionals of the refugee center (medical staff and interpreters). For example, interviewees frequently expressed their concern about their children in relation to the risk of AIDS. The participants, all Iraqi people who freshly arrived in The Netherlands and preparing themselves for a permanent stay in a new country, expected their children to be confronted with new life styles and different sexual norms and values. Most participants received no sexual education when they were young but believed that their children should be educated and be warned for the potential dangers of unsafe sex. Therefore, we added some questions about the intention to discuss AIDS and safe sex with children.

\subsection{Study 2: Methods}

\subsubsection{Research setting}

The second study was conducted at a refugee center that hosts groups of varying nationality on invitation of the Dutch Government. The center provides medical assistance and prepares refugees for living in The Netherlands. In general, refugees stay about 6-7 weeks in the center, before they are allocated a permanent place to live. The center offers a variety of courses, such as Dutch language courses, and also organizes an AIDS education session to be attended to on a voluntary basis. The aim and content of the education session were generally the same as the meeting described in Study 1 . There were different meetings for men and women and the gender of the group was matched with the gender of the AIDS advisor. About 10 participants at a time attended the education sessions. 


\subsubsection{Design and procedures}

The design of the second study resembles the design of the first study. About 2 weeks before the AIDS information meeting participants filled out a pretest questionnaire whereas posttest data were gathered 2 weeks afterwards. An extension to the first study is that half of the subjects received information from a LHA whereas the other half received information from a Dutch public health nurse and an interpreter (both male or female depending on the gender of the group). Four health advisors agreed to participate in our study: a male and a female Iraqi advisor (the LHAs) and a male and female Dutch nurse (the professional health advisors or PHAs).

The AIDS information meeting was announced at information boards and at various courses. The nurses, medical doctor and interpreters also invited people personally. If people were interested, they could sign up for the information meeting at the secretary's office. Subsequently, participants were randomly assigned to the LHA or the Dutch nurse (a list with names was composed and the first was assigned to the LHA, the second to the Dutch nurse, the third to the LHA, and so on). All participants received a written invitation for a specific meeting. Together with the invitation, they received the pretest questionnaire and they were asked to return it as soon as possible in a special box at the secretaries office. All questionnaires were returned before the AIDS education sessions started.

Both the pretest and posttest questionnaire intended to measure knowledge about HIV and AIDS, and the attitude, social norm, perceived behavioral control and intention toward condom use. The posttest also included questions about openness about AIDS to children. The questionnaire of Study 1 was adjusted to the Iraqi participants on the basis of open interviews of the target group. These (individual) pilot interviews were held with a group of Iraqi refugees that left the center before the second group of Iraqi refugees arrived under which the main study was performed. The wording of the questions and the answering categories were adjusted in cooperation with two Iraqi interpreters. The interpreters explicitly advised to replace a regular answering scale varying from highly disagree to highly agree by the categories absolutely not, I don't think so, neutral, not bad and sure and indeed. According to the interpreters, such a scale better captures the intended meaning of the original scale than a literal translation.

We tested the differences between the pretest, posttest and type of health advisor in 2 (Time : pretest versus posttest) $\times$ 2 (Advisor: lay health advisor versus professional health advisor) analyses of variance. In this design, Time is a within-subjects comparison and Advisor a between-subjects comparison.

\subsubsection{Measures}

About the same questionnaires were used as in Study 1 (see Section 2.1.3). On advice of Iraqi interpreters the answering scales were rephrased (see Section 2.3) and a few questions were rephrased or omitted. A series of statements were added to both the pretest and posttest questionnaire in order to measure openness to children to discuss AIDS. The following statements were used: "I think it is necessary to discuss AIDS with my children", "I want to know all about AIDS because I want to be able to discuss the issue with my children", "Educating children about AIDS is a task of the parents", and "If one of my children wants to discuss AIDS, I will do so". The mean score of the answers on the four statements was computed to create an openness scale. Cronbach's alphas were 0.62 at pretest and 0.71 at posttest.

\subsection{Study 2: Results}

Participants. A total of 36 Iraqi men were present at the AIDS session and filled out both the pretest and posttest questionnaire. About two-thirds participants were between 20 and 30 years old $(63.1 \%), 36.9 \%$ was between 30 and 50. Fifty-eight percent of the participants were married, $42 \%$ was not married. We extensively tried to stimulate women to participate, but no more than three women attended the AIDS session and answered both the pre- and posttest. A first reason for the low participation of women was the use of written questionnaires (several women were illiterate and therefore not able to fill out the questionnaires). Another reason was the nature of the education issue. Women hesitated to attend a meeting about AIDS and some men more or less forbade their wives and daughters to visit the meeting. The men indicated that they would pass the information on to their families. Because of low participation rates, the data from women were omitted from the analyses. We will come back to this issue in the discussion.

Knowledge about AIDS: Analysis of the knowledge index resulted in a main effect of Time $(F(1,34)=26.18$; $P<0.001)$ and an effect of Advisor $(F(1,34)=4.00 ; P=$ 0.053). At posttest participants answered more questions correctly than at pretest ( $M$ pretest $12.4, M$ posttest 14.9 ). Inspection of Advisor effect indicated that participants in the lay health advisor group had more knowledge about AIDS than in the professional health advisor group (see Table 2). However, these effects were qualified by an interaction effect of Time and Advisor indicating that participants in the PHA group acquired more knowledge than participants in the LHA group $(F(1,34)=4.03 ; P<0.05)$. As shown in Table 2, the greater increase knowledge of PHA participants is caused by their lower initial knowledge level. Because of the random selection procedure, this difference must be considered as coincidental. The reported effects did not interact with age or sex.

Attitude towards condom use: The main effect of Time showed that both participants advised by a LHA or a PHA had a more favorable attitude at posttest than at pretest $(M$ pretest $3.50, M$ posttest $3.86 ; F(1,34)=10.78 ; P<0.01$ ). The amount of attitude change did not depend on the type of health advisor (see Table 2), nor with age or marital status. 
Table 2

Means and standard deviation of knowledge about AIDS, attitude, social norm, behavioral control, intention and openness to children at pretest and posttest for the LHA group and the PHA group (Study 2)

\begin{tabular}{|c|c|c|c|c|}
\hline & \multicolumn{4}{|c|}{ Advisor group } \\
\hline & \multicolumn{2}{|c|}{ LHA $(n=21)$} & \multicolumn{2}{|c|}{ PHA $(n=15)$} \\
\hline & $M$ & S.D. & $M$ & S.D. \\
\hline \multicolumn{5}{|c|}{ Knowledge about AIDS } \\
\hline Pretest & 13.3 & 2.46 & 11.2 & 3.19 \\
\hline Posttest & 15.0 & 1.50 & 14.7 & 1.53 \\
\hline \multicolumn{5}{|l|}{ Attitude } \\
\hline Pretest & 3.47 & 0.79 & 3.54 & 0.57 \\
\hline Posttest & 3.78 & 0.73 & 3.97 & 0.35 \\
\hline \multicolumn{5}{|c|}{ Social norm } \\
\hline Pretest & 3.19 & 1.20 & 2.69 & 1.80 \\
\hline Posttest & 3.55 & 0.78 & 3.23 & 1.11 \\
\hline \multicolumn{5}{|c|}{ Behavioral control } \\
\hline Pretest & 3.24 & 0.75 & 2.79 & 0.89 \\
\hline Posttest & 3.20 & 0.79 & 3.22 & 0.72 \\
\hline \multicolumn{5}{|l|}{ Intention } \\
\hline Pretest & 2.38 & 1.29 & 2.36 & 1.09 \\
\hline Posttest & 2.58 & 1.45 & 2.81 & 1.21 \\
\hline \multicolumn{5}{|c|}{ Openness to children } \\
\hline Pretest & 4.01 & 0.63 & 4.33 & 0.74 \\
\hline Posttest & 4.49 & 0.53 & 4.39 & 0.55 \\
\hline
\end{tabular}

Note: Knowledge about AIDS scores vary from 0 (no correct answers) to 16 (all answers correct). Judgments on the remaining variables were made on 5-point scales (1: absolutely not, 5: sure and indeed).

Social norm: A main effect of Time $(F(1,32)=4.98$; $P<0.05)$ indicated that the perceived social norm was more favorable at posttest than at pretest (M's 3.00 and 3.44, respectively). Change in social norm was not related to type of health advisor (see Table 2), or with age or marital status.

Perceived behavioral control: The perceived behavioral control was 3.05 on the pretest and 3.21 on the posttest, a non-significant difference; $F(1,30)=1.07$; n.s. (see Table 2). The effects of Advisor and the Time by Advisor interaction were also non-significant $\left(F^{\prime} \mathrm{s}<1\right.$; n.s. $)$. There were no differences with respect to age or marital status.

Intention to use condoms: The mean intention scores were 2.38 on the pretest and 2.67 on the posttest (see Table 2), a non-significant difference $(F(1,34)=1.12 ; n . s$. $)$. The effect of Advisor $(F(1,34)=1.30 ; n . s$.$) and the Time by Advisor$ interaction were also non-significant $(F(1,34)=1.56$; n.s. $)$. There were no interactions with age and marital status.

Openness to children: We found a significant effect of Time $(F(1,34)=5.15 ; P<0.05)$ and a marginally significant interaction effect of Time and Advisor $(F(1,34)=$ 3.07; $P=0.08)$. The main effect of Time indicated an increasing willingness to be open to children about AIDS ( $M$ pretest 4.14, $M$ posttest: 4.45 ). Inspection of the means suggested that increase was mainly due to LHA participants. At pretest, LHA participants' willingness to be open was lower than that of PHA participants whereas posttest scores were
Table 3

Correlations of determinants with the intention of to use condoms for the total group of participants and the LHA and PHA groups separately

\begin{tabular}{lccc}
\hline & $\begin{array}{c}\text { Total group } \\
(n=36), R\end{array}$ & $\begin{array}{l}\text { LHA } \\
(n=21), r\end{array}$ & $\begin{array}{l}\text { PHA } \\
(n=15), r\end{array}$ \\
\hline Pretest & & & \\
Knowledge & $0.43^{*}$ & $0.41^{*}$ & $0.45^{*}$ \\
Attitude & 0.23 & 0.09 & 0.15 \\
social norm & 0.15 & 0.10 & 0.23 \\
Behavioral control & 0.29 & 0.11 & -0.12 \\
Posttest & & & $0.67^{*}$ \\
Knowledge & $0.56^{*}$ & $0.48^{*}$ & 0.30 \\
Attitude & $0.41^{*}$ & $0.44^{*}$ & -0.19 \\
Social norm & -0.28 & -0.38 & 0.31 \\
Behavioral control & 0.12 & -0.01 & \\
\hline \multicolumn{1}{c}{$*<0.05}$. & & &
\end{tabular}

* $P<0.05$.

about the same (see Table 2). There were no effects of age and marital status.

Prediction of intention to condom use: Because of the relatively small sample size, a correlational analysis was used to establish the relation of the intention to use condoms with knowledge about AIDS, attitude, social norm and perceived behavioral control (see Table 3). We computed different correlational analyses for the total group and the LHA and PHA group separately, on both pretest and posttest data. At pretest, there was a significant relation between the knowledge about AIDS and the intention to use condoms for both LHA and PHA participants. At posttest, knowledge about AIDS remained related to intention but for the LHA group the attitude became also significant related to intention.

\subsection{Discussion Study 2}

In accordance with Study 1, Study 2 also shows positive effects of the AIDS education session. Participants were more knowledgeable about AIDS and HIV afterwards, and the attitude and social norm toward condom use became more positive. In contrast to Study 1 , we observed no changes in intention and perceived behavioral control toward condom use. We did not find clear evidence that lay health advisors are more effective than professional health advisors, or vice versa. The increase of knowledge was bigger for participants advised by a Dutch professional, but this difference can be explained by the (coincidental) lower initial knowledge level of PHA participants. Another difference is that LHA participants become more convinced of the necessity to be informed about AIDS in order to discuss the issue with their children than they were before.

The correlational analysis predicting the intention to use condoms showed interesting results. At pretest, intention was positively related to knowledge about AIDS for both LHA and PHA participants. At posttest, intention was again positively related to knowledge about AIDS for both LHA and PHA participants. However, only for LHA participants we observed a relation between intention and attitudes 
as well. This may be interpreted as evidence that AIDS education sessions facilitated by a LHA results in more internally motivated decisions to use condoms in order to protect oneself from AIDS, as compared to PHA-based AIDS sessions. In other words, PHAs and LHAs are equally successful in providing knowledge but LHA-based sessions are more successful in convincing participants to use condoms.

\subsection{General discussion and conclusion}

The two studies reported here, both show positive effects of group education sessions on AIDS. Both studies show an increase of knowledge about HIV and AIDS and more positive perceptions of the use of condoms. Study 2 shows that lay health advisors are equally successful at achieving change as trained professionals. Moreover, our results suggest that LHAs and PHAs instigate different processes of change. That is, as compared to PHA guided sessions, the intention to use condoms of participants who attended to a LHA guided session are stronger based on their own perceptions, beliefs and convictions of condom use. This relation was found in Study 1 and replicated in Study 2, but only for the participants who attended to the LHA sessions. The fact that the cultural background of participants varied considerably indicates that this finding is not tied to one, specific culture. The finding that LHAs do achieve positive change seems even more promising if we take into account that they were less experienced than the PHAs in Study 2. The Dutch professionals had a medical background and were highly experienced in advisory work. Moreover, the PHAs were assisted by interpreters. It is possible that the interpreters provided not only a literal, but also a cultural translation of the information.

A limitation of Study 2 is the fact that the research population was male. Despite the interest they expressed in the interviews preceding Study 2, women did not visit the meetings or did not participate in our Study. It remains somewhat unclear whether women did not want to participate themselves or whether their husbands would not allow them to visit the education sessions. As mentioned before, some men told us that they considered the sessions not necessary for their wives because they would pass on all information. Probably, the introduction of the session as "AIDS information sessions" was too explicit for these Islamic women (or their husbands).

In further research, it will be interesting to study longer term effects and to examine whether the persistence of effects is related to the cultural similarity or dissimilarity of the AIDS advisor. Further research should also address whether or not people talk with other people about the issue, and whether they are more perceptive to further information and activities. Another advantage of LHA-based programs might be a trickle down effect of the meetings: remarkably, the male participants in Study 2 express a higher willingness to discuss AIDS and AIDS prevention with their children.

\section{Conclusion}

The present two studies show that LHAs are at least as effective in transmitting AIDS-related information as experts and that LHAs might be more persuasive in terms of behavioural change, especially when it concerns communication AIDS risks to others. Of course, at present it is unknown whether a combinatory effort of LHAs and PHAs could even be more productive. On the basis of the data presented and the literature, it seems that the cultural and social similarity of LHAs offers a crucial advantage in health promotion strategies.

\subsection{Practical implications}

Until date, little systematic research exists that examines the effectiveness of lay health advisors versus professional advisors in the field of health education for migrants. The two studies reported here make such an attempt but more studies are needed to provide conclusive evidence. Such evaluation studies should use an adequate experimental design including, a control group and a sufficient sample size, and should focus on a comparison of results obtained by lay health advisors and professional health advisors. In these studies and the education programs, great care should be taken to involve women. It is possible that the participation of women will probably benefit from a more indirect approach. For example, other studies show that migrant women are interested in information about childcare and education [23]. Perhaps, a better strategy to inform women about AIDS is to incorporate AIDS education in sessions about childcare and education. Another advantage of such a strategy is that husbands probably have no objections to their wives and daughters attending these kinds of education sessions.

\section{Acknowledgements}

We are grateful to Karen Bree, Hilda van't Riet and Ping Robbers for their assistance with the organisation of Study 2.

\section{References}

[1] Central Bureau of Statistics. Statistical yearbook. Voorburg/Heerlen, The Netherlands: CBS; 2000.

[2] Dutch Immigration and Naturalization Services. Jaarverslag van de Immigratie-en Naturalisatiedienst over 1998 [Annual report 1998 of the Immigration and Naturalization Services]. The Hague, The Netherlands: DINS; 1999.

[3] Voorham AJJ, Van Haastrecht PM. Gezondheidsbevordering: gekleurde samenleving, motor voor verandering [Health promotion: colored community, driving force for change]. In: Haveman HB, Uniken Venema P, editors. Migrants and health promotion. Houten/Diegem, The Netherlands: Bohn, Stafleu \& Van Loghum; 1996.

[4] Kocken PL, Voorham AJJ. Effects of peer-led AIDS education aimed at Turkish and Moroccan male migrants in The Netherlands: a 
randomized control evaluation study. Eur J Public Health 2001;11:153-9.

[5] Van Haastrecht PM, Voorham AJJ. Gezondheidsvoorlichting: handboek interculturele zorg [Health education: handbook intercultural care]. Utrecht, The Netherlands: Uitgeverij de Tijdstroom; 1996.

[6] Haour-Knipe M, Fleury F, Dubois-Arber F. HIV/AIDS prevention for migrant and ethnic minorities: three faces of evaluation. Soc Sci Med 1999;49:1357-72.

[7] Service C, Salber E. Community health education: the lay health advisor approach. Durham, NC: Duke University Health Care System; 1979.

[8] NIGZ. Tien jaar voorlichting in de eigen taal en cultuur over gezondheid en opvoeding [Ten years of education on health and child rearing in the own language and culture]. Woerden, The Netherlands: NIGZ; 1998.

[9] Bergshoeff EPJ. Groepsvoorlichting aan Turkse en Marokkaanse vrouwen: Een onderzoek naar groepsvoorlichting in eigen taal en cultuur bij eerstelijns-gezondsheidszorg-instellingen in Amsterdam [Group health education for Turkish and Moroccon women: a study at group education in the own language and culture at primary health service centers in Amsterdam]. Amsterdam, The Netherlands: Buro GVO; 1993.

[10] Singels L. De Turkse en Marokkaanse gezondheidsvoorlichtster in de praktijk: verslag van een onderzoek naar de gezondheidsvoorlichting in eigen taal voor en door Turkse en Marokkaanse vrouwen [The Turkish and Morrocan health advisor in practice: research report on health education in the own language by and for Turkish and Morrocan women]. Utrecht, The Netherlands: Bureau Voorlichting Gezondheidszorg Buitenlanders; 1993.

[11] Eng E, Parker E, Harlan C. Lay health advisor intervention strategies: a continuum from natural helping to paraprofessional helping. Health Educ Behav 1997;24:413-7.

[12] Janz NK, Zimmerman MA, Wren PA, Israel BA, Freudenberg N, Carter RJ. Evaluation of 37 AIDS prevention projects: successful approaches and barriers to program effectiveness. Health Educ Q 1996;23:80-97.

[13] Watkins AL, Harlan C, Eng E, Gansky SA, Gehan D, Larson K. Assessing the effectiveness of lay health advisors with migrant farm workers. Fam Commun Health 1994;16:72-87.

[14] Earp JAL, Viadro CI, Vincus AA, Altpeter M, Flax V, Mayne L, et al. Lay health advisors: a strategy for getting the word out about breast cancer. Health Educ Behav 1997;24:432-51.

[15] Baker EA, Bouldin N, Durham M, Escobar Lowell M, Gonzales M, Jodaitis N, et al. The latino health advocacy program: a collaborative lay health advisor approach. Health Educ Behav 1997;24:495-509.

[16] Rickert V, Jay M, Gottlieb A. Effects of peer-counseled AIDS education program on knowledge, attitudes, and satisfaction of adolescents. J Adolesc Health 1991;12:38-43.

[17] Rijke B, De Vries NK. Peers doen het beter ...! Peer-voorlichting bij jongeren [Peers do it better ...! Peer education for adolescents]. Tijds voor Gezondheidsbevordering 1995;16:103-16.

[18] Bernert DJ, Mouzon LD. Peer education in the 90's: a literature review of utility and effectiveness. Health Educ 2001;2:31-7.

[19] Ajzen I. Attitudes, personality, and behavior. Chicago, IL: Dorsey; 1988.

[20] Richard R, Van der Pligt J, De Vries NK. Anticipated affective reactions and prevention of AIDS. Br J Soc Psychol 1995;33:405-18.

[21] Schaalma H, Kok GJ, Peters L. Determinants of consistent condom use by adolescents: the impact of experience of sexual intercourse. Health Educ Res 1993;8:225-69.

[22] Godin G, Maticka-Tyndale E, Adrien A, Manson-Singer S, Willms D, Cappon P. Cross-cultural testing of three social cognitive theories: an application to condom use. J Appl Soc Psychol 1996;26:1556-86.

[23] Voets A. Gezondheidsvoorlichting voor migrantenvrouwen in Haarlem: een evaluatie van het project gezondheidsvoorlichting in de eigen taal en cultuur voor Turkse en Marokkaanse vrouwen [Health education for female migrants: an evaluation of the project health education own culture and language for Turkish and Moroccan women]. Haarlem, The Netherlands: Bureau Onderzoek \& Statistiek; 1996. 